\title{
EFICIÊNCIA QUÂNTICA DO FOTOSSISTEMA II DE MUDAS DE ABACAXIZEIRO 'IMPERIAL' EM RESPOSTA A ASSOCIAÇÃO COM Piriformospora indica E HERBICIDAS ${ }^{1}$
}

\author{
LANA IVONE BARRETO CRUZ², MARIA DO CÉU MONTEIRO CRUZ², \\ EVANDER ALVES FERREIRA², GUILHERME DUMBÁ MONTEIRO DE CASTRO², \\ MIRIELLE DE OLIVEIRA ALMEIDA²
}

\begin{abstract}
RESUMO - O objetivo foi avaliar o efeito dos herbicidas diuron, ametryn e sulfentrazone, e da associação micorrízica na eficiência quântica do fotossistema II de mudas de abacaxizeiro 'Imperial'. Foi utilizado o esquema de parcela subdividida, tendo na parcela o fatorial $2 \times 4$, sendo dois tipos de mudas: inoculadas com $P$. indica e sem inoculação, e quatro doses de herbicidas: $0 ; 1,5 ; 3,0$ e 6,0 $\mathrm{L} \mathrm{ha}^{-1}$ para o ametryn, $0 ; 1,6$; 3,2 e $6,4 \mathrm{~L} \mathrm{ha}^{-1}$ para o diuron e $0 ; 0,4 ; 0,8$ e $1,6 \mathrm{~L} \mathrm{ha}^{-1}$ para o sulfentrazone, e na subparcela as épocas de avaliação, distribuídos no delineamento inteiramente casualizado, com três repetições. Os herbicidas foram aplicados ao substrato antes do plantio das mudas. A inoculação com o fungo $P$. indica foi feita no momento do plantio. A avaliação da eficiência quântica foi feita por meio da razão de fluorescência da clorofila $a$ (Fv/Fm), determinada aos 60; 90 e 120 dias após o plantio das mudas, obtendo-se a fluorescência inicial, máxima, e variável. Os dados obtidos foram submetidos à análise de variância e regressão polinomial. O herbicida ametryn não comprometeu a eficiência do fotossistema II das mudas de abacaxizeiro inoculadas com o fungo $P$. indica. A inoculação com fungo $P$. indica aumentou a eficiência do fotossistema II das mudas. A aplicação dos herbicidas diuron e sulfentrazone em doses elevadas reduziu a eficiência do fotossistema II de mudas de abacaxizeiro 'Imperial' não inoculadas com o fungo $P$. indica.
\end{abstract}

Termos para indexação: Ananas comosus, associação micorrízica, fluorescência da clorofila.

\section{QUANTUM EFFICIENCY OF PHOTOSYSTEM II OF 'IMPERIAL' PINEAPPLE NURSERY IN RESPONSE TO ASSOCIATION WITH THE Piriformospora indica AND HERBICIDE}

\begin{abstract}
The aim to evaluate the effect of diuron, sulfentrazone in ametryn herbicides and mycorrhizal association in quantum efficiency of photosystem II of 'Imperial' pineapple nursery. The split-split plot scheme was used, taking in plot the $2 \times 4$ factorial, being the factors two types of nursery pineapple: inoculated with $P$. indica and without inoculation and four doses of herbicides: $0,1.5,3.0$ and $6.0 \mathrm{~L} \mathrm{ha}^{-1}$ for ametryn, $0,1.6,3.2,6.4 \mathrm{~L} \mathrm{ha}^{-1}$ for diuron and $0,0.4,0.8$ and $1.6 \mathrm{~L} \mathrm{ha}^{-1}$ for sulfametrazone and the sub-plot evaluation times, distributed in a completely randomized design with three replications. Herbicides were applied to the substrate before planting of pineapple nursery. Inoculation with the fungus $P$. indica it was made at the time of planting. The evaluation of quantum efficiency was taken as the ratio chlorophyll $a$ fluorescence $(\mathrm{Fv} / \mathrm{Fm})$, determined at 60, 90 and 120 days after planting of the nursery pineapple, determining the initial fluorescence, maximal and variable. Data were submitted to analysis of variance and regression. Herbicide ametryn did not affect the photosystem II efficiency of pineapple nursery associated with the fungus $P$. indica. Inoculation with the fungus $P$. indica increased the photosystem II efficiency. The diuron and sulfentrazone herbicides application at high doses decreased in photosystem II efficiency of 'Imperial' pineapple nursery without inoculation with the fungus $P$. indica.
\end{abstract}

Index terms: Ananas comosus, mycorrhizal association, chlorophyll fluorescence.

\footnotetext{
1(Trabalho 411-13). Recebido em: 16-10-2013. Aceito para publicação em: 19-07-2014.

${ }^{2}$ Mestranda do Programa de Pós-graduação em Produção Vegetal - PPGPV, UFVJM, Diamantina-MG. Bolsista CAPES. E-mail: lanabiologia@gmail.com,

${ }^{3}$ Dr $^{\mathrm{a}}$., Prof . do PPGPV, UFVJM, Diamantina-MG. E-mail: mariceu@oufvjm.edu.br

${ }^{4}$ Pós-doutorando do PPGPV, UFVJM. Bolsista CAPES. E-mail: evanderalves@yahoo.com.br

${ }^{5}$ Graduandos do Curso de Agronomia, UFVJM, Diamantina-MG. Bolsistas FAPEMIG. E-mails: dumba12@hotmail.com; mirioliveiraalmeida@yahoo.com.br.
} 


\section{INTRODUÇ̃̃O}

A análise da fluorescência da clorofila $a$ vem sendo amplamente utilizada no entendimento dos mecanismos da fotossíntese e na avaliação da capacidade fotossintética alterada por estresses bióticos ou abióticos a que as plantas são submetidas, como a deficiência hídrica (CRUZ et al., 2009), temperatura (OLIVEIRA et al., 2002), radiação (MAZZA et al., 2000) e herbicidas (CATUNDA et al., 2005).

Em condições de ambientes estressantes, ocorre o decréscimo na eficiência quântica potencial do fotossistema II, que pode ser detectada pela queda na relação Fv/Fm (KRAUSE; WEIS, 1991). Assim, uma das formas de monitorar a resposta das plantas às variações no ambiente de cultivo tem sido a utilização de medidas da fluorescência da clorofila $a$ associada ao fotossistema II.

No sistema moderno de produção, a utilização de fungos micorrízicos tem favorecido a formação de mudas de diversas espécies e cultivares, entre as quais a de abacaxizeiro 'Smooth Cayenne' (SANTOS et al., 2011). Isso ocorre porque os fungos penetram nas raízes, atuando como um sistema radicular adicional, o que contribui para aumentar o volume radicular efetivamente ocupado no solo e melhorar a capacidade das plantas em absorver nutrientes, em especial o fósforo, beneficiando o crescimento $\mathrm{e}$, consequentemente, o vigor e a produtividade (MOREIRA; SIQUEIRA, 2006).

Para a abacaxicultura, o uso dessa técnica pode viabilizar a formação de mudas, proporcionando aumento na produtividade do viveiro e menor tempo de produção, pois a aquisição de material propagativo sadio é proveniente da cultura de tecidos (BALDOTTO et al., 2010), mudas que, geralmente, apresentam o crescimento lento quando comparadas às demais formas de propagação.

Além da aquisição de mudas sadias, o uso de herbidas é uma prática realizada para reduzir a competição com as plantas daninhas por água e nutrientes. Esse manejo permite o bom desenvolvimento da cultura, em decorrência da menor dependência de mão de obra, além de viabilizar a redução dos custos de produção (MAIA et al., 2012).

Entretanto, os efeitos da utilização de herbicidas sobre os organismos presentes no solo ainda são desconhecidos. Alguns pesquisadores apontam a necessidade de estudos sobre a ação dos diversos agroquímicos utilizados na agricultura, a fim de se entender os processos biológicos que são alterados, visando a compreender e a utilizar de forma benéfica as novas interações surgidas nesse sistema (ROSA et al., 2010).

Dentre os herbicidas utilizados no cultivo do abacaxizeiro, o ametryn e o diuron interferem na síntese de clorofila, alterando o funcionamento dos cloroplastos (FAYEZ, 2000). Esses herbicidas podem afetar a formação de outros pigmentos, como xantofilas (VÁRADI et al., 2000) e carotenoides (KIM et al., 2004), causando interferência no fluxo de elétrons (WAKABAYASHI; BÖGER, 2004). E outros, como sulfentrazone, podem modificar a síntese de intermediários utilizados no processo fotossintético, em virtude de a produção de clorofila ser inibida pelo bloqueio da rota (DUKE et al., 1991).

Em algumas circunstâncias, a aplicação de herbicidas, mesmo quando o sintoma não é visível, causa injúrias ao aparelho fotossintético, reduzindo a capacidade de realização de fotossíntese pela planta (BARBAGALLO et al., 2003). E em função disso, tem-se observado declínio nos teores de pigmentos fotossintéticos, podendo ser letal para a planta, haja vista a redução nos teores de clorofilas $a$ e $b$ e carotenoides, demonstrando certa seletividade de alguns herbicidas à cultura do abacaxizeiro.

Diante do exposto, o trabalho foi realizado com o objetivo de avaliar o efeito dos herbicidas diuron, ametryn e sulfentrazone e da associação micorrízica na eficiência do fotossistema II de mudas de abacaxizeiro 'Imperial'.

\section{MATERIAL E MÉTODOS}

A pesquisa foi conduzida em casa de vegetação utilizando mudas de abacaxizeiro 'Imperial' (Ananas comosus (L.) Merril) produzidas e multiplicadas in vitro. As variações de temperaturas máxima e mínima no interior da casa de vegetação durante a realização do trabalho foram monitoradas por meio de termo-higrômetro digital, modelo MT 240 MINIPA (Figura 1).

Foi utilizado o esquema de parcela subdividida, tendo na parcela o fatorial $2 \times 4$, sendo os fatores referentes a dois tipos de mudas: inoculadas com o $P$. indica e sem inoculação e quatro doses de herbicidas recomendados para a cultura do abacaxizeiro, e na subparcela, as épocas de avaliação, distribuídos no delineamento inteiramente casualizado, com três repetições, e a unidade experimental constituída por três vasos com uma muda de abacaxizeiro. Para os herbicidas testados, as doses do produto comercial foram: $0 ; 1,5 ; 3,0$ e 6,0 $\mathrm{L} \mathrm{A}^{-1}$ para o ametryn, $0 ; 1,6 ; 3,2$ e $6,4 \mathrm{~L} \mathrm{ha}^{-1}$ para o diuron e $0 ; 0,4 ; 0,8$ e $1,6 \mathrm{~L} \mathrm{ha}^{-1}$ para o sulfentrazone.

O substrato utilizado para o plantio das mudas foi o Bioplant ${ }^{\circledR}$, o qual foi previamente autoclavado durante uma hora, a $180^{\circ} \mathrm{C}$. Após a autoclavagem, foi realizado o enchimento dos sacos de polietileno com capacidade $0.1 \mathrm{dm}^{3}$.

Antes do plantio das mudas, foi feita a aplicação dos herbicidas, utilizando-se de um pulverizador com pressão constante de 3 bar, equipado com barra com duas pontas TT 11002, espaçadas de $0,5 \mathrm{~m}$ e volume de calda de $150 \mathrm{~L} \mathrm{ha}^{-1}$.A aplicação 
dos herbicidas foi realizada cerca de 24 horas antes do plantio, deixando-se os vasos em ambiente aberto.

A inoculação com o fungo $P$. indica foi feita no momento do plantio, sendo utilizados discos de micélio contendo estruturas fúngicas de $5 \mathrm{~mm}$ de diâmetro retirado da borda da colônia.

Após o plantio em casa de vegetação, as mudas passaram por um período de aclimatização durante dois meses, mantidas sob $50 \%$ de sombreamento e frequência controlada de irrigação por aspersão. Após este período, foi retirado o sombrite e a irrigação foi realizada apenas uma vez ao dia.

Depois que as mudas estavam aclimatizadas, as plantas de todos os tratamentos receberam uma solução preparada com $10 \mathrm{mg} \mathrm{L}^{-1}$ de $\mathrm{N}$ e $1,85 \mathrm{mg}$ $\mathrm{L}^{-1}$ de $\mathrm{K}$, via fertirrigação, uma vez por semana, até o final do experimento.

A determinação da fluorescência da clorofila $a$ foi realizada no terço médio da folha ' $\mathrm{D}$ ' das mudas de abacaxizeiro com o auxílio de um fluorômetro portátil de luz modulada MINI-PAM ${ }^{\circledR}$, aos 60;90 e 120 dias após o plantio, após as 20h, quando os centros de reações se encontravam completamente abertos com perda mínima de calor, determinandose a fluorescência inicial $\left(\mathrm{F}_{0}\right)$, fluorescência máxima $\left(\mathrm{F}_{\mathrm{m}}\right)$ e eficiência quântica do fotossistema II,dada pela razão $\mathrm{F}_{\mathrm{v}} / \mathrm{F}_{\mathrm{m}}$. A fluorescência variável $\left(\mathrm{F}_{\mathrm{v}}\right)$ é dada pela diferença entre $\mathrm{F}_{0}$ e $\mathrm{F}_{\mathrm{m}}$.

Após as avaliações das fluorescências, foi realizada a análise da colonização, retirando as plantas do substrato de cultivo, e as raízes foram separadas e lavadas em água corrente e fixadas com formol-ácido acético. Para avaliar a colonização, fragmentos de, aproximadamente, $1 \mathrm{~cm}$ de comprimento das raízes finas foram clarificados com $\mathrm{KOH}(10 \%)$ e corados com azul de tripano em lactoglicerol a $0,05 \%$ e, com o auxílio de uma lupa Optech 40X, a colonização radicular foi observada.

Os dados obtidos foram submetidos à análise de variância e regressão polinomial. A escolha dos modelos foi baseada no potencial para explicar o fenômeno biológico, no coeficiente de determinação e na significância dos coeficientes de regressão, utilizando o teste " $\mathrm{t}$ ", considerando $p \leq$ 0,05 de probabilidade de erro. Para comparar mudas inoculadas, foi realizada comparação de médias, considerando $p \leq 0,05$ de probabilidade de erro, pelo teste de F.

\section{RESULTADOS E DISCUSSÃO}

Foi observada interação entre as épocas de avaliação (60; 90 e 120 dias após a aplicação dos herbicidas) e doses dos herbicidas aplicadas e as inoculações para a Fluorescência inicial $\left(\mathrm{F}_{0}\right)$ nos cultivos com aplicação de ametryn, diuron e sulfentrazone, para a Fluorescência máxima $\left(\mathrm{F}_{\mathrm{m}}\right)$ nos cultivos com a aplicação de diuron e sulfentrazone e para a eficiência do fotossistema II $\left(\mathrm{F}_{\mathrm{v}} / \mathrm{F}_{\mathrm{m}}\right)$ no cultivo com a aplicação de sulfentrazone.

$\mathrm{Na}$ análise de colonização do sistema radicular, verificou-se a associação do $P$. indica com as raízes do abacaxizeiro na presença dos três herbicidas testados. Além disso, foi observado que o fungo colonizou as raízes das mudas cultivadas com a aplicação de todas as doses dos herbicidas. Esse comportamento evidencia que os herbicidas não interfiram na associação do $P$. indica com o abacaxizeiro, visto que os efeitos da simbiose podem diferir conforme a combinação fungo/planta/ condições do meio de cultivo.

Quanto à eficiência do fotossistema II, no cultivo com a aplicação de ametryn, observou-se que as mudas sem inoculação não apresentaram diferenças significativas em nenhuma das épocas avaliadas (Figura 2). Nas mudas associadas com o P. indica, a eficiência do fotossistema II foi $10,84 \%$, $11,42 \%$ e $15,29 \%$ maior quando se aplicou a dose de $6 \mathrm{~L} \mathrm{ha}^{-1}$ em relação ao rendimento das mudas sem o herbicida, aos 60 (Figura 2a), 90 (Figura 2b) e 120 (Figura 2c) dias após o plantio, respectivamente.

No cultivo com aplicação do diuron, aos 60 dias, foi observada nas mudas não inoculadas a redução de $10 \%$, alcançando o valor de 0,69 na eficiência do fotossistema II com a dose de 6,4 L $\mathrm{ha}^{-1}$ em relação à testemunha (Figura $3 \mathrm{a}$ ), enquanto as mudas inoculadas com o $P$. indica apresentaram acréscimos de 5,91\% e 31,43\%, estimados com as doses de 3,51 L ha-1 e 4,23 $\mathrm{L} \mathrm{ha}^{-1}$ aos 90 e 120 dias após a aplicação, respectivamente (Figuras 3b e 3c).

Nas mudas cultivadas com a aplicação do sulfentrazone, observou-se que as inoculadas apresentaram incremento no rendimento do fotossistema II em todas as épocas avaliadas. Aos 60 dias, a relação $\mathrm{F}_{\mathrm{v}} / \mathrm{F}_{\mathrm{m}}$ alcançou valores de 0,78 nas mudas associadas com o $P$. indica (Figura 4a) e a dose de 1,6 $\mathrm{L} \mathrm{ha}^{-1}$; aos 90 dias, o valor de 0,80 (Figura 4b) e 0,76 aos 120 dias (Figura 4c) com a dose média de $0,63 \mathrm{~L} \mathrm{ha}^{-1}$. No entanto, as mudas que não foram inoculadas apresentaram decréscimo linear com o aumento das doses de herbicida, aos 90 e 120 dias após o plantio, comparadas com as mudas do tratamento-testemunha. Nessas épocas, a relação $\mathrm{F}_{\mathrm{v}} / \mathrm{F}_{\mathrm{m}}$ foi reduzida de 0,79 para 0,74 e de 0,75 para 0,69 , respectivamente, com a aplicação da dose de 1,6 $\mathrm{L} \mathrm{ha}^{-1}$ (Figuras 4b e 4c).

O comportamento da eficiência do fotossistema II pode ser explicado pelas alterações observadas na fluorescência inicial $\left(\mathrm{F}_{0}\right)$ e máxima $\left(\mathrm{F}_{\mathrm{m}}\right)$. Com a aplicação dos herbicidas, observouse, nas mudas que não foram inoculadas, maiores alterações na $\mathrm{F}_{0}$, principalmente aos 90 dias após o plantio, quando se verificou aumento da $\mathrm{F}_{0}$ até a dose de 2,98 $\mathrm{L} \mathrm{ha}^{-1}$ do ametryn (Figuras 5b), a partir da dose de 3,25 $\mathrm{L} \mathrm{ha}^{-1}$ do diuron (Figura 5e) e aumento linear de $125 \%$ com a aplicação $1,6 \mathrm{~L}$ 
ha ${ }^{-1}$ de sulfentrazone, em relação ao tratamentotestemunha, aos 90 e 120 após o plantio (Figuras 5h e 4i), enquanto nas mudas inoculadas com o fungo $P$. indica $\mathrm{a}_{0}$ foi reduzida ou não variou com o aumento da dose dos herbicidas (Figura 5).

As diferenças observadas na $\mathrm{F}_{0}$ em relação às mudas inoculadas sugerem que a associação micorrízica contribuiu para evitar dano no centro de reação do fotossistema II, pois as mudas que não foram colonizadas apresentaram aumento da $F_{0}$ com a aplicação dos hebicidas diuron e sulfentrazone. Geralmente, o aumento da $\mathrm{F}_{0}$ ocorre quando os centros de reação do fotossistema II estão comprometidos, ou a transferência da energia de excitação da antena para os centros de reação está prejudicada (BAKER; ROSENQVIST, 2004).

Outro aspecto notado em relação às variações da $\mathrm{F}_{0}$ refere-se à época, observando-se as maiores alterações nos valores da $F_{0}$ aos 90 dias após o plantio, ocasião em que a casa de vegetação alcançou maiores temperaturas (Figura 1).

O comportamento foi semelhante em relação às alterações na fluorescência máxima $\left(\mathrm{F}_{\mathrm{m}}\right)$, observando-se as maiores variações aos 90 dias, sendo as mudas que apresentaram os menores valores da $\mathrm{F}_{0}$ as que alcançaram os maiores resultados da $\mathrm{F}_{\mathrm{m}}$ (Figura 6). Observou-se em plantas inoculadas com o fungo o $P$. indica, sob efeito do ametryn e do sulfentrazone, aumento linear da $\mathrm{F}_{\mathrm{m}}$ com o aumento das doses dos hercidas (Figuras $6 \mathrm{~b}$ e $6 \mathrm{~h}$ ), e com a aplicação do diuron ocorreu aumento até a dose de $2,1 \mathrm{Lha}^{-1} \mathrm{e}$ naquelas que não foram inoculadas houve redução de $57,9 \%$ com a aplicação de $6,4 \mathrm{~L} \mathrm{ha}^{-1} \mathrm{em}$ relação ao tratamento-testemunha (Figura 6e).

Pelos resultados observados em relação à $\mathrm{F}_{\mathrm{m}}$, a aplicação do diuron em doses elevadas reduziu a $F_{m}$ nas mudas de abacaxizeiro em todas as épocas avaliadas (Figuras 6d, 6e e 6f). Essas variações sugerem que pode ter ocorrido, logo após o plantio das mudas, alterações nas propriedades dos aceptores de elétrons do FSII, causadas por mudanças conformacionais no principal constituinte do complexo proteico que forma o FSII, a proteína D1 (BULKHOV et al., 1999). Isso pode ter ocorrido porque o diuron é um inibidor da transferência de elétrons no fotossistema II que impede a redução da quinona $\mathrm{A}$, por competir com a quinona $\mathrm{B}$ pelo sítio de ligação à proteína D1 (FUERST; NORMAN, 1991), o que ocasiona a saída de QB e, consequentemente, interrupção no fluxo de elétrons, não permitindo com isso a redução do NADPH, a qual é essencial para a fixação de $\mathrm{CO}_{2}$ (BREITENBACH et al., 2001).

Essa alteração na fase incial do crescimento das mudas, possivelmente, torna-as menos competitivas pelos recursos do meio, e quando expostas às variações do ambiente de cultivo (Figura 1) podem expressar de forma diferenciada seu metabolismo, visto que a $\mathrm{F}_{\mathrm{m}}$ é um dos parâmetros utilizados para compreender o estado das plantas em relação ao seu metabolismo e deste com o ambiente em que se encontra, pois ela reflete a condição da planta naquele momento (BAKER, 2008).

Outro aspecto importante observado foi que as mudas associadas ao $P$. indica apresentaram aumento nos valores da $\mathrm{F}_{\mathrm{m}}$. com a aplicação dos herbicidas, exceto para as doses mais altas do diuron, sugerindo que a associação micorrízica favoreceu a manutenção do metabolismo das mudas sob efeito dos herbicidas. Além disso, as alterações que ocorreram na $\mathrm{F}_{\mathrm{m}}$ nas diferentes épocas, podem também estar relacioanadas com as variações de temperatura ao longo do período de avaliação, pois aos 100 dias após o plantio ocorreram dias nublados, com baixa irradiância, o que contribuiu para a redução das temperaturas no interor da casa de vegetação(Figura 1).

Esses resultados sugerem que as variações observadas na $\mathrm{F}_{\mathrm{m}}$ nas mudas inoculadas, principalmente aos 60 e 120 dias (Figuras $7 \mathrm{a}$ e $7 \mathrm{c})$, não chegaram a comprometer o rendimento do fotossisma II, provalmente porque as alterações observadas não caracterizaram dano no centro de reação do fotossistema II.

De maneira geral, as variações observadas nas mudas que não foram inoculadas caracterizaram um estresse químico que comprometeu seu crescimento, pois a eficiência quântica máxima do fotossistema II $\left(\mathrm{F}_{\mathrm{v}} / \mathrm{F}_{\mathrm{m}}\right)$ pode variar de 0,75 a 0,85 em plantas não submetidas a estresses, sendo considerado para a maioria das espécies, entre 0,78 e 0,83 (OSMOND, 1994). A redução dessa razão é um indicador de efeito inibitório, quando as plantas estão submetidas ao estresse (ARAUS; HOGAN, 1994). Nas condições em que foi realizado este trabalho, os menores valores da $F_{v} / F_{m}$ foram observados nas mudas que não foram inoculadas, com valores mínimos de 0,65 aos 90 dias após o plantio no cultivo com ametryn , 0,69 nas mudas que receberam a dose de $6,4 \mathrm{~L} \mathrm{ha}^{-1}$ aos 60 dias no cultivo com diuron e 0,69 nas mudas que receberam a dose de 1,6 $\mathrm{L} \mathrm{ha}^{-1}$ do herbicida aos 120 dias no cultivo com sulfentrazone.

Diversas circunstâncias evidenciam variações na relação $F_{v} / F_{m}$ quando as plantas são submetidas a uma condição de estresse. Em abacaxizeiro cultivados com a aplicação dos herbicidas amicarbazone e diuron + paraquat, a razão $\mathrm{F}_{\mathrm{v}} / \mathrm{F}_{\mathrm{m}}$ chegou 0,66 e 0,19 , respectivamente, enquanto sob condições normais de cultivo o valor era de 0,80 (CATUNDA et al., 2005). 


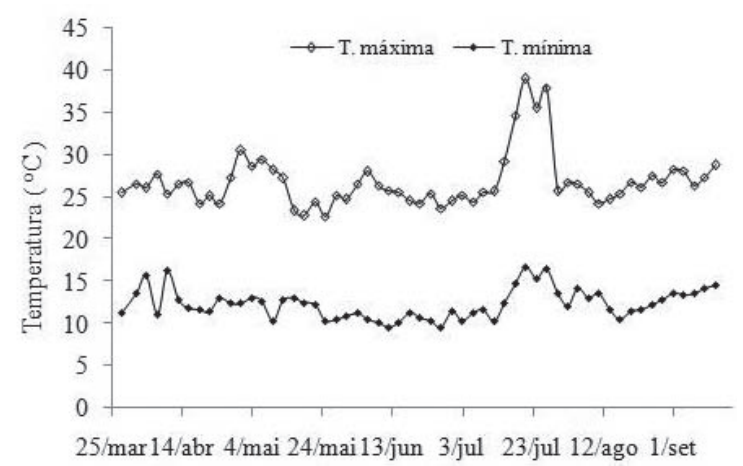

FIGURA 1- Variações das temperaturas máxima e mínima que ocorreram no interior da casa de vegetação durante o período de aclimatização e crescimento das mudas de abacaxizeiro 'Imperial'.

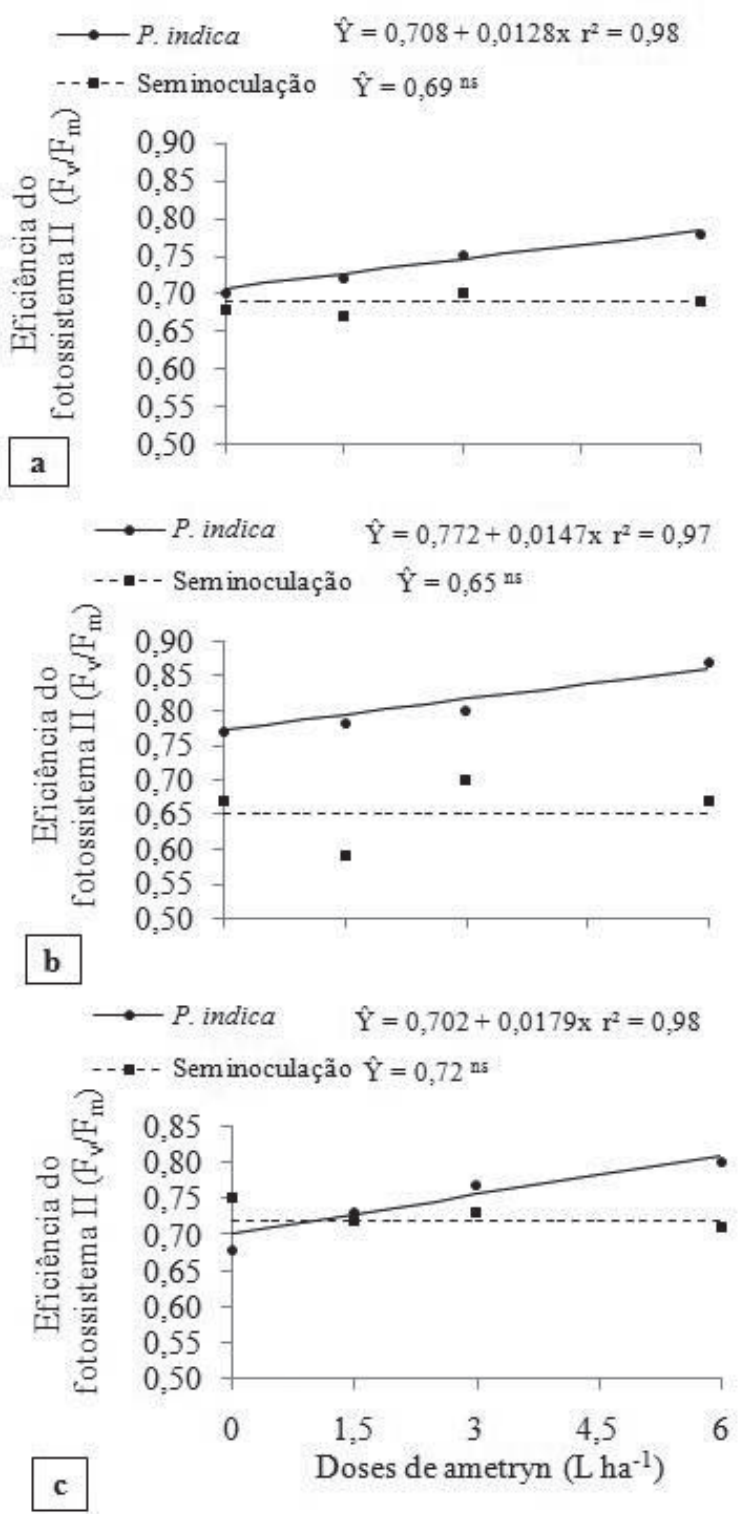

FIGURA 2- Eficiência do fotossistema II em abacaxizeiro 'Imperial' inoculado com o fungo Piriformospora indica, aos 60 (a), 90 (b) e 120 (c) dias após a aplicação do herbicida ametryn. 


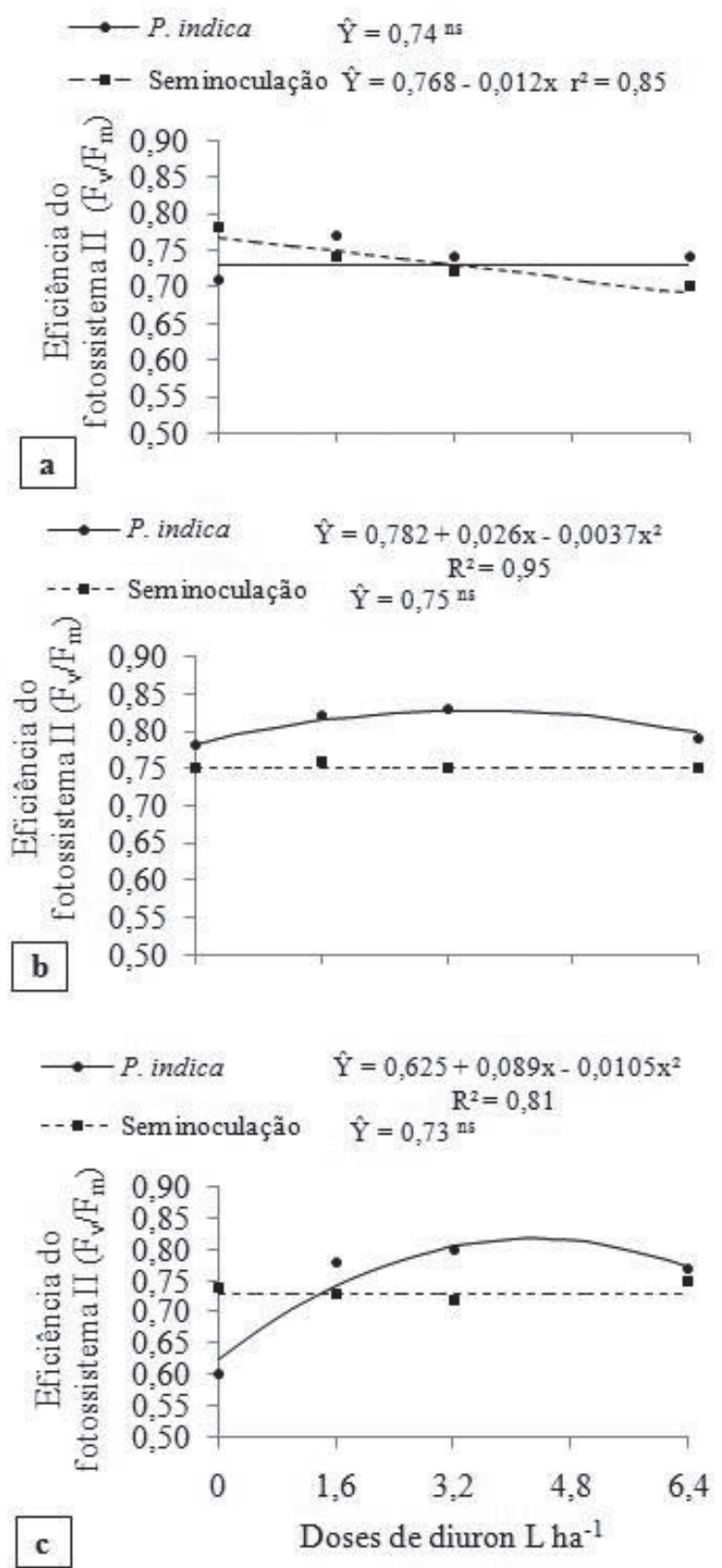

FIGURA 3- Eficiência do fotossistema II em abacaxizeiro 'Imperial' inoculado com o fungo Piriformospora indica, aos 60 (a), 90 (b) e 120 (c) dias após a aplicação do diuron. 

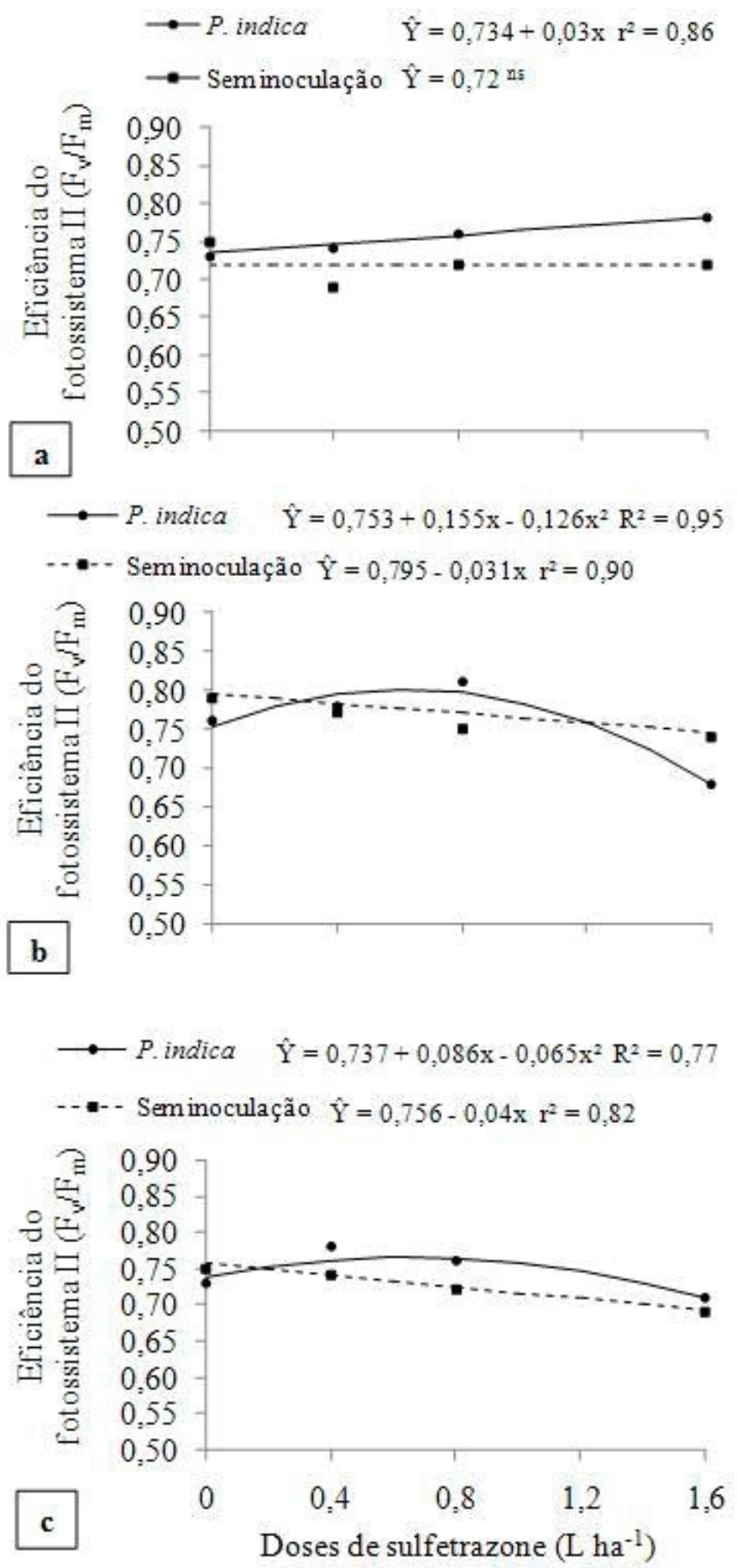

FIGURA 4- Eficiência do fotossistema II em abacaxizeiro 'Imperial' inoculado com o fungo Piriformospora . indica, aos 60 (A), 90 (B) e 120 (C) dias após a aplicação do sulfentrazone. 


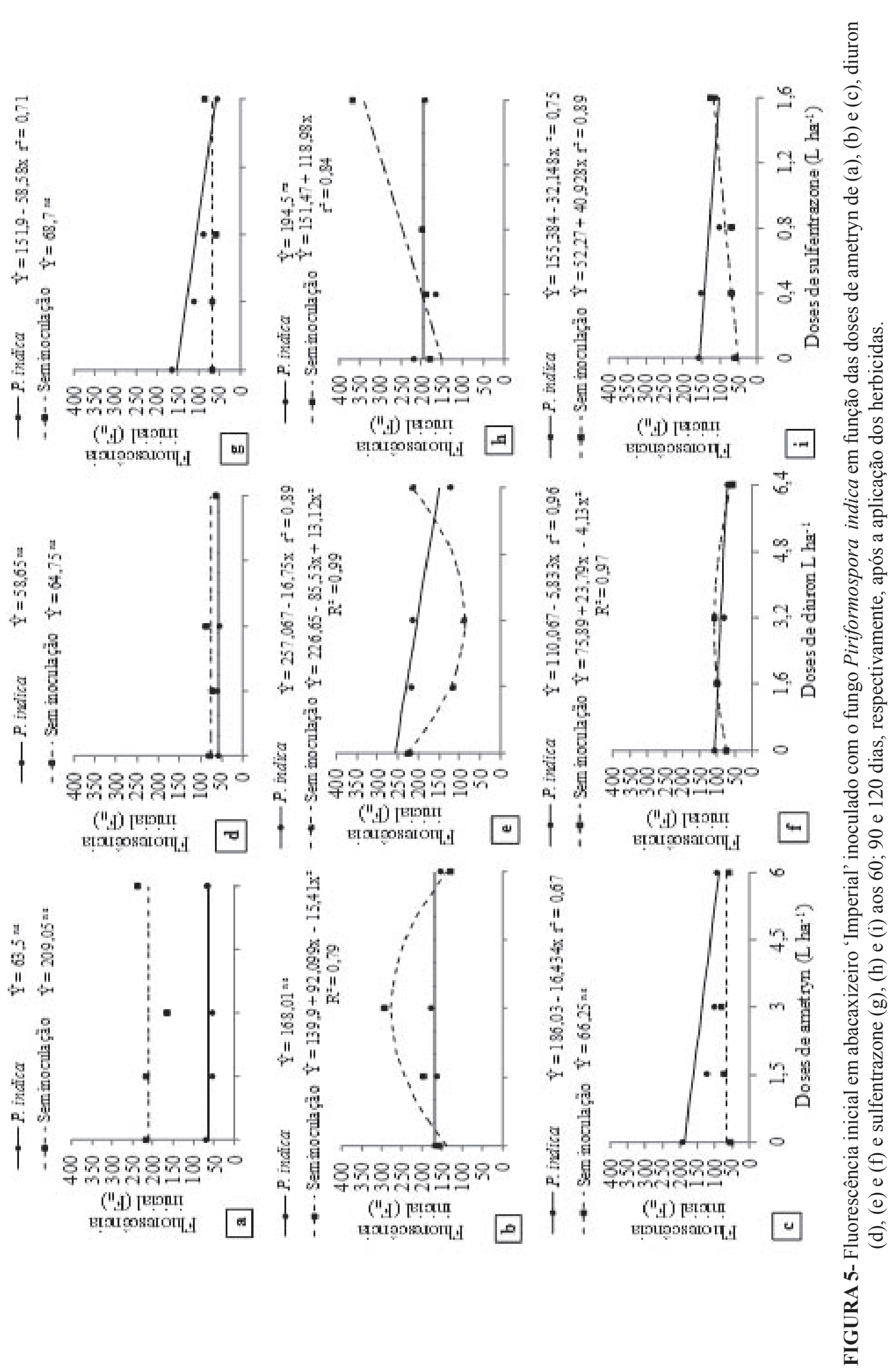




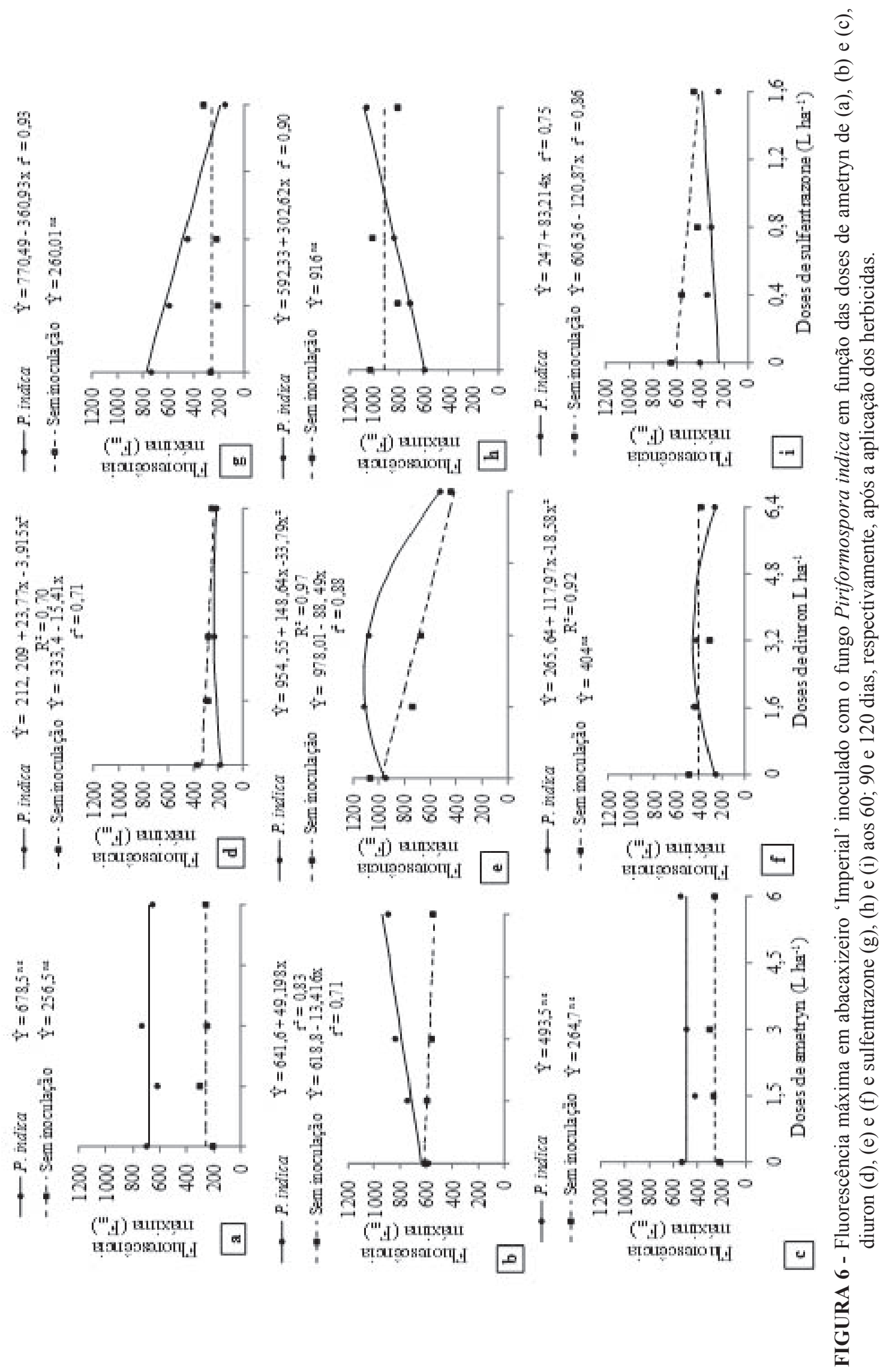




\section{CONCLUSÕES}

O herbicidas ametryn não compromete a eficiência do fotossistema II das mudas de abacaxizeiro 'Imperial' associadas com o fungo Piriformospora indica.

A inoculação com o fungo $P$. indica aumenta a eficiência do fotossistema II.

A aplicação dos herbicidas diuron e sulfentrazone em doses elevadas reduz a eficiência do fotossistema II de mudas de abacaxizeiro 'Imperial' não inoculadas com o fungo $P$. indica.

\section{REFERÊNCIAS}

ARAUS, J. L.; HOGAN, K. P. Leaf structure and patterns of photoinhibition in two neotropical palms in clearings and forest understory during the dry season. American Journal of Botany, Iowa, v.81, n.6, p.726-738, 1994.

BAKER, B. Chlorophyll fluorescence: A probe of photosynthesis in vivo. Annual Review of Plant Biology, Boca Raton, v.59, p.89-113, 2008.

BAKER, N.R.; ROSENQVIST, E. Applications of chlorophyll fluorescence can improve crop production strategies: an examination of future possibilities. Journal of Experimental Botany, Oxford, v.55, p.1607-1621, 2004.

BAldotTO, L. E. B.; BAldotTO, M. A.; OLIVARES, F. L.; VIANA, A.P.; BRESSANSMITH, R. Seleção de bactérias promotoras de crescimento no abacaxizeiro cultivar Vitória durante a aclimatização. Revista Brasileira de Ciência do Solo, Viçosa,MG, v.34, n.2, p. 349-360, 2010.

BARBAGALLO, R. P.; OXBOROUGH, K.; PALLETT, K. E.;BAKER, N. R. Rapid, noninvasive screening for perturbations of metabolism and plant growth using chlorophyll fluorescence imaging. Plant Physiology, Belmont, v. 132, n. 2, p. 485496, 2003.

BREITENBACH, J.; ZHU, C.; SANDMAN, G. Bleaching herbicide norflurazon inhibits phytoenedesaturase by competition with the cofactors. Journal of Agricultural and Food Chemistry, Washington, v.49, n.11, p.5270-5272, 2001 .
BULKHOV, N.; WIESE, C.; NEIMANIS, S. Heat sensitivity of chloroplasts and leaves: Leakage of protons from thylakoids and reversible activation of cyclic electron transport. Photosynthesis Research, New York, v.59, p.81-93, 1999.

CATUNDA, M. G.; FREITAS, S. P.; OLIVEIRA, J. G.; SILVA, C. M. M. Efeitos de herbicidas na atividade fotossintética e no crescimento de abacaxi (Ananas comosus). Planta Daninha,Viçosa, MG, v.23, n.1, p.115-121, 2005.

CRUZ, M. C. M.; SIQUEIRA, D. L.; SALOMÃO, L. C.C.; CECON, P. R. Fluorescência da clorofila $a$ em folhas de tangerineira 'Ponkan' e limeira-ácida 'Tahiti' submetidas ao estresse hídrico. Revista Brasileira de Fruticultura, Jaboticabal, v.31, n.3, p.896-901, 2009.

DUKE, S. O.; LYDON, J.; BECERRIL, J. M; SHERMAN, T. D.; LEHNEN JR., L. P.; MATSUMOTO, H. Protoporphyrinogen oxidase inhibiting herbicides. Weed Science, Boston, v.39, n.3, p.465-473, 1991.

FAYEZ, K. A. Action of photosynthetic diuron herbicide on cell organelles and biochemical constituents of the leaves of two soybean cultivars. Pesticide Biochemistry Physiology, Philadelphia, v.66, n.2, p.105-115, 2000.

FUERST, E. P.; NORMAN, M.A. Interactions of herbicides with photosinthetic electron transport. Weed Science, Boston, v.39, n.3, p.458-464. 1991.

KIM, J. S.; YUN, B.; W.; CHOI, J.S.; KIM, T. J.; KWAK, S.S.; CHO, K. Y. Death mechanisms caused by carotenoid biosynthesis inhibitors in green and in undeveloped plant tissues. Pesticide Biochemistry and Physiology, Philadelphia, v.78, n.3, p.127-139, 2004.

KRAUSE, G. H.; WEIS, E. Chlorophyll fluorescence and photosynthesis: the basics. Annual Review of Plant Physiology and Plant Molecular Biology, Palo Alto, v.42, p.313-349, 1991.

LEONARDO, F. A. P.; PEREIRA, W. E.; SILVA, S. M.; COSTA, J. P. Teor de clorofila e índice SPAD no abacaxizeiro cv. vitória em função da adubação nitrogenada. Revista Brasileira de Fruticultura, Jaboticabal, v.35, n.2, p.377-383, 2013. 
MAIA, L. C. B., MAIA, V.; M.; LIMA, M. H. M.; ASPIAZÚ, I.; PEGORARO, R. F. Growth, production and quality of pineapple in response to herbicide use. Revista Brasileira de Fruticultura, Jaboticabal, v.34, n.3, p.799-805, 2012.

MAZZA, C. A.; BOCCALANDRO, H. E.; GIORDANO C. V.; BATTISTA, D.; SCOPEL, A. L.; BALLARÉ, C. L. Functional significance and induction by solar radiation of ultraviolet-absorbing sunscreens in field-grown soybean crops. Plant Physiology, Minneapolis, v.122, n.1, p.117-126, 2000.

MOREIRA, F. M. S.; SIQUEIRA, J. O. Microbiologia e bioquímica do solo. 2. ed. Lavras: Editora UFLA, 2006. 729p.

OLIVEIRA, J. G.; AlveS, P. L. C. A.; MAGALHÃES, A. C. The effect of chilling on the photosynthetic activity in coffee (Coffea arabica L.) seedlings. The protective action of chloroplast pigments. Brazilian Journal Plant Physiology, Campos dos Goytacazes, v.14, n.2, p.95-104, 2002.

OSMOND, C.B. What is photoinhibition? Some insights from comparisons of shade and sun plants. In: BAKER, N.R.; BOWYER, J.R. (Ed.). Photoinhibition of photosynthesis, from molecular mechanisms to the field. Lancaster: Scientific Publishers, 1994. p.1-24.
ROSA, D. D.; BASSETO, M. A.; CAVARIANI, C.; FURTADO, E. L. Efeito de herbicidas sobre agentes fitopatogênicos. Acta Scientiarum. Agronomy, Maringá. v.32, n.3, p.379-383, 2010.

SANTOS, P. C.; FREITAS, M. S. M.; FREITAS, S. J.; SILVA, M. P. S.; BERILLI, S.S. Fungos micorrízicos no crescimento e nutrição de rebentos oriundos de coroa de abacaxi. Revista Brasileira de Fruticultura, Jaboticabal, v.33, p.658-665, 2011. Volume especial.

VÁRADI, G.; DARKÓ, E.; LEHOCZKI, E. Changes in the xanthophyll cycle and fluorescence quenching indicate light dependent early events in the action of paraquat and the mechanism of resistance to paraquat in Erigeron Canadensis (L.) Cronq. Plant Physiology, Belmont, v.123, n.4, p.1459-1469, 2000.

WAKABAYASHI, K.; BÖGER, P. Phytotoxic sites of action for molecular design of modern herbicides (Part 1): the photosynthetic electron transport system. Weed Biology Management, Malden, v.4, n.1, p.818, 2004. 